\title{
Analysis on How to Deal with Grain Futures Options within China
}

\author{
Wenyou Gao ${ }^{1}$ \\ ${ }^{1}$ School of Economics and Management, Chang Chun University of Science and Technology, Chang Chun, Jilin, \\ 130022, China \\ Correspondence: Wenyou Gao, School of Economics and Management, Chang Chun University of Science and \\ Technology, Chang Chun, Jilin, 130022, China. E-mail: mhymark@gmail.com
}

Received: September 15, 2014

Accepted: September 25, 2014

Online Published: October 8, 2014

doi:10.5430/afr.v3n4p86

URL: http://dx.doi.org/10.5430/afr.v3n4p86

\begin{abstract}
A kind of financial derivative named Option is one of the greatest invention of Man-kinds in the field of Finance, which can secure the profits and returns of investors, traders and producers with lower cost basis .Certainly, the Grain Futures Options are able to benefit farmers, relevant producers and traders, furthermore pushing the Real Economy of one country into the process of benign cycle. However, up to now, we can not find the related tradings and platforms within China. By viewing and introducing the transaction of Grain Futures Options in the developed countries, the paper analyzed how to price and deal with this kind of financial derivative. The author hopes the paper will make contributions to changing the development of China's agricultural production for the better, furthermore enriching varieties of China's financial markets.
\end{abstract}

Keywords: Generalized autoregressive conditional heteroskedasticity, Drift rate, Variance rate, Standard normal distribution function, Maximum-likelihood estimates

\section{Introduction}

\subsection{What is Grain Futures Options (GFO)?}

The so-called GFO is a kind of financial derivative with commodity attribute, whose underlying assets is agricultural products futures. This kind of derivative also has strike price, expiration date as well as call and put forms, each form has two positions, therefore four sides included — for call : long and short positions ; for put : long and short positions . For most of China's investors and traders, short position is not suitable for them because of lacking pricing capabilities, so I hereby emphasize on illustrating the rights of long position - If you were to buy a call or put GFO, in a certain period of time, you would have a set of selective rights as follows:

In or before the maturity date, on the grain futures market, you could buy or sell a quantity of related future products;

At the same time, compared to strike price, if current future prices were not ideal, you might also have the right to give up on delivery or taking delivery;

Moreover, various options in the hands could be sold to others before the expiration date of option.

In the 18th century, among the Japanese cities, such as Osaka rice market, there had been an early organized pattern about grain options trading; however, its main intelligence, development and relevant tradings have always been in the U.S. Market . At one time during the financial crisis in the 1930s, the Commodity Exchange Act (1936) banned this kind of derivative instrument ; in February of 1973, the Chicago Board Options Exchange began to open and start such deals again. In the current situation, GFO tradings in all developed countries have made considerable development, while, the fact that vast majority of such trading platforms in the terminal markets are almost within the United States is indisputable.

\subsection{Demerits of the Option Compared with Futures}

Options and futures are inseparable, both have risk-hedging functions. But for futures market: hedging risks means writing off returns and profits simultaneously; as well, the relative required initial margin is bigger , "threshold" is higher, so not suitable for ordinary investors ; in addition, with too much leverage and margin system, future market-to-market mechanism makes investors and traders face the risk of "blowing up"-all of these are future's disadvantages. On the contrary, without the aforesaid future's demerits, the options market can gather more investors, collect more money, therefore offering a wider room for long-short positions with call and put tradings. Meanwhile, 
above everything else, creation of grain futures options can benefit Chinese agricultural producing and marketing enterprises, especially small and medium-sized ones. As well, GFO can setup a good platform, on which Chinese farmers can protect their expectation without losing most of their returns and profits.

\subsection{Further Exploration on the Reason Why China Should Create GFO Tradings}

As is known to all, every year the agricultural planting and production under the premise of profit-pursuing are somewhat at a random rate, so makes part of of agricultural products in short supply or too much supply, thus making relevant prices fall or rise dramatically, accordingly relevant individuals and companies would suffer huge losses .Futures can be used to adjust market, but its higher margin and mark-to-market system make itself not applicable to small and medium-sized investors and producers .In order to hedging the aforesaid problems, creating options to stabilize related prices of agricultural products, safeguarding farmer's expectations for their own product and avoiding random-planting risks have become more and more important .

The problem here is: how to deal with GFO in the relevant market? The concrete pattern will be shown on the basis of an example.

\subsection{Trading Pattern of GFO in CBOT}

Figure 1 is a snap-shot picture from CBOT Corn Options Premium Chart, which is dated on January 12, 2007, and February 23. The according call and put options included 3- month, 5- month, and 7- month ones

According to the figure: contract size is 5,000bus.(bushel)/order; 1 Bus. of Corn corresponding to 1 cent ; U.S. DOLLAR $1=100$ Cents $\rightarrow$ so the relative leverage factor is 50 .

On 12. January, taking the example of a call option with strike price $\$ 380$-if the investors bought a 3- month contract, the number in relative Cell (by referring to the 4th row and the 2nd column under Call Option) was $\$ 35.5$, multiplied by 50 (corn options trading leverage), the price, or the premium of the call option, which you should pay, was $\$ 1775.00$; as the time decayed, on February 23, 2007, $\$ 380$ strike of 3-month call option's premium rose to $\$ 64.250$, then total sum of the price was $\$ 3212.50$ (64.25 x 50), set the value of GFO as Y:

$\mathrm{Y}=\$ 3212.50-\$ 1775.00=\$ 1437.50$,

Subtracting the Exchange cost- $\$ 200$,

Investor's net profit $=\$ 1237.50$

The rest under each strike price had the same way in which the gain and loss could be calculated, note: the returns of put options were also the efforts of the later price minus the previous price- don't be confused with put option pricing.

While, compared to different intervals of strike prices, how does we price different options accordingly? What particularity is there in pricing GFO ? All of the related problems are relevant to option pricing mechanism; for pricing problem, once you get a good solution, to create GFO tradings within China will come to be feasible.

Contract Size: 5,000 bus.(bushel); Cent/Bus. ; Tick Size $=0.125$ cent

1). $2007 / 1 / 12$

CALL OPTION

\begin{tabular}{|l|l|l|l|}
\hline Months & $\begin{array}{l}3 \text { months of } \\
2007\end{array}$ & $\begin{array}{l}5 \text { months of } \\
2007\end{array}$ & $\begin{array}{l}7 \text { months of } \\
2007\end{array}$ \\
\hline $\begin{array}{l}\text { Last Closing } \\
\text { Future Price }\end{array}$ & 396.50 & 407.50 & 414.50 \\
\hline Deadline & Feb.23,2007 & Apr.20,2007 & Jun.22,2007 \\
\hline 380.00 & $\mathbf{3 5 . 5 0 0}$ & 47.000 & 57.000 \\
\hline 390.00 & 32.000 & 43.000 & 52.875 \\
\hline 400.00 & 29.250 & 39.375 & 49.500 \\
\hline
\end{tabular}


PUT OPTION

\begin{tabular}{|l|l|l|l|}
\hline Validity & $\begin{array}{l}\text { March } \\
\text { of } 2007\end{array}$ & $\begin{array}{l}\text { May } \\
\text { of 2007 }\end{array}$ & $\begin{array}{l}\text { July } \\
\text { of 2007 }\end{array}$ \\
\hline $\begin{array}{l}\text { Last Closing } \\
\text { Future Price }\end{array}$ & 396.50 & 407.50 & 414.50 \\
\hline Deadline & Feb.23,2007 & Apr.20,2007 & Jun.22,2007 \\
\hline 380.00 & 5.500 & 8.875 & 13.500 \\
\hline 390.00 & 8.000 & 12.500 & 17.500 \\
\hline 400.00 & 12.625 & 16.500 & 21.000 \\
\hline
\end{tabular}

2). $2007 / 2 / 23$

\section{CALL OPTION}

\begin{tabular}{|l|l|l|l|}
\hline Validity & $\begin{array}{l}\text { May } \\
\text { of } 2007\end{array}$ & $\begin{array}{l}\text { July } \\
\text { of } 2007\end{array}$ & $\begin{array}{l}\text { September } \\
\text { of 2007 }\end{array}$ \\
\hline $\begin{array}{l}\text { Current Future } \\
\text { Price }\end{array}$ & 442.50 & 452.00 & 435.50 \\
\hline Deadline & Apr.20,2007 & Jun..22,2007 & Aug..24,2007 \\
\hline 380.00 & $\mathbf{6 4 . 2 5 0}$ & 76.000 & 68.875 \\
\hline 390.00 & 55.375 & 68.000 & 63.000 \\
\hline 400.00 & 47.125 & 60.875 & 57.500 \\
\hline
\end{tabular}

PUT OPTION

\begin{tabular}{|l|l|l|l|}
\hline Validity & $\begin{array}{l}\text { May } \\
\text { of } 2007\end{array}$ & $\begin{array}{l}\text { July } \\
\text { of } 2007\end{array}$ & $\begin{array}{l}\text { September } \\
\text { of } 2007\end{array}$ \\
\hline $\begin{array}{l}\text { Current Future } \\
\text { Price }\end{array}$ & 442.50 & 452.00 & 435.50 \\
\hline Deadline & Apr.20,2007 & Jun..22,2007 & Aug..24,2007 \\
\hline 380.00 & 2.250 & 4.875 & 14.500 \\
\hline 390.00 & 3.250 & 6.625 & 18.500 \\
\hline 400.00 & 5.000 & 9.125 & 23.000 \\
\hline
\end{tabular}

Resource : http://www.options.co.jp

\section{Figure 1. CBOT. CORN OPTION PREMIUM CHART}

\section{How to Price the Option based on B-S-M Model}

Among the various option's pricing models, in terms of efficacy, Black-Schoels - Merton model (generally called Black Model) is more simple and rational. At the same time, in view of the futures products as a kind of underlying assets, the model can more quickly and more reasonably price for the relative option-according to its intrinsic value and time value, by using the Risk-Neutral and No-Arbitrage Principle .

According to ITO lemma, the price $F$ of the underlying assets-agricultural products futures, is a kind of random variable, which adopts the rules of Geometric Brownian Motion. However, by viewing different drift rate and variance rate, the future's commodity attribute and its financial characteristics make itself differ from Stock Index, Stock, Foreign Exchange Futures, Interest Rate Futures, etc. Since agricultural products belong to consumer products, and after harvest, they need drying, packing, storage and so on , which will experience multiple working procedure, therefore, such futures should take the factor cost of carry into consideration-let's set $u$ as an expression form of current cash-flow of the cost, $S$ for the spot price of agricultural products, $r$ for risk-free compound rate, so is: 


$$
F \leq(S+u) e^{r \Delta t}
$$

Thinking about its financial attribute and convenience for pricing agricultural products futures, the value of $\mathrm{F}$ takes upper limit, which is:

$$
F=(S+u) e^{r \Delta t}
$$

Assuming $c$ as call option price of agricultural products futures:

$$
c=e^{-r \Delta t}\left[F N\left(d_{1}\right)-X N\left(d_{2}\right)\right]
$$

Meanwhile, $p$ for put option price of agricultural products futures:

$$
p=e^{-r \Delta t}\left[X N\left(-d_{2}\right)-F N\left(-d_{1}\right)\right]
$$

Where, $d_{1}, d_{2}$ for the standard normal distribution function $\rightarrow$

$$
\begin{gathered}
d_{1}=\frac{\ln (F / X)+\left(\frac{\sigma^{2}}{2}\right) \Delta t}{\sigma \sqrt{\Delta t}} \\
d_{2}=d_{1}-\sigma \sqrt{\Delta t}
\end{gathered}
$$

Among them, the $\mathrm{X}$ is the futures Strike Price; $\sigma$ is the volatility of relevant returns rate - in the course of pricing the options, how to determine the volatility of GFO is one of the most crucial factors, so to speak: there were no volatility, option pricing model would make no sense.

\section{Dimension Metrics on Volatility of Grain Futures}

As mentioned above, for the various option pricing models, how to determine volatility of the returns from underlying asset price is very important. By viewing varieties of methods: Historical Volatility Model is relatively simple, but with a lag, it does not have forecast function; the world's major financial institutions more prefer to Generalized Autoregressive Conditional Heteroscedasticity (GARCH) Model to measure the volatility. The inferring process is very complex, in short, that is:

$$
\sigma_{n}^{2}=\gamma V_{L}+\alpha U_{n-1}^{2}+\beta \sigma_{n-1}^{2}
$$

Where, all of the parameters are referring as $: V_{L} \rightarrow$ long-term implied average daily volatility ; $\sigma_{n}^{2} \rightarrow$ the fluctuation variance rate of the nth day's futures price yield; $U_{i} \rightarrow$ the rate of yield, and :

$$
U_{i}=\frac{F_{i}-F_{i-1}}{F_{i-1}}, i=1,2, \ldots n
$$

Assuming $\gamma V_{L}=w$, then:

$$
\sigma_{n}^{2}=w+\alpha U_{n-1}^{2}+\beta \sigma_{n-1}^{2}
$$

The most important thing of the above equation is how to determine the value of each parameter, therefore, the method of maximum- likelihood estimates should be utilized, while, setting the value of the Estimation as $\mathrm{P} \rightarrow$

$$
P=\sum_{i=1}^{m}\left[-\ln \left(v_{i}\right)-\frac{U_{i}^{2}}{v_{i}}\right], v_{i}=\sigma_{i}^{2},
$$

So , based on the maximum likelihood estimates ,the value of $w, \alpha, \beta$ will be out of numerical.

Whereas, $\gamma V_{L}=w$, then $\rightarrow$

$$
V_{L}=\frac{w}{\gamma}=\frac{w}{1-\alpha-\beta}
$$

From $V_{L}$, we can measure long-term, average, implied and daily volatility. Based on $V_{L}$, we will obtain the value of instantaneous volatility $V(t)$, then through the method of Changing Integral (or Minato Integral method ), the annualized volatility can be derived at last - setting volatility for a year as $\sigma(T)$, then 


$$
\sigma^{2}(T)=252\left\{V_{L}+\frac{1-e^{a T}}{a T}\left[V(0)-V_{L}\right]\right\}
$$

Whereby, $\quad a=\ln \frac{1}{\alpha+\beta}, V(0)=E\left(\sigma_{n}^{2}\right)=\sigma_{n}^{2}$

If so, week-month-volatility can be converted to "annualized" volatility .It is important to note here: 252 is the actual trading days in 1 year within the U.S., however, different countries have different situations; At the same time, since the velocity of $\sigma$ is higher than that of the scalar time, therefore, in volatility transformation of different periods, we should be subject to the formula $\sigma \sqrt{\Delta t}$ for it.

\section{GPO's Hint to Chinese Financial Sectors}

The inventors of Black Model were awarded the Nobel Prize in economics, because they created the feasible pricing model for Options to be traded on Exchanges. With the constant improvement of the financial system in developed countries, in view of their financial support to the department of industrial and agricultural production, especially referring as how to serve small and medium-sized relevant enterprises, I feel, the financial security mechanism in some developed countries is much more mature than us; as well, by taking a look at our country's economy, the development, the implementation and innovation of related financial products or derivative instruments have not gone far enough.

From researching delisting warrants and many problems arising from creation of currency options (stared on April 11, 2011), excluding other factors, I think that: it is the pricing problem that is not solved well, especially the volatility measurement is not very scientific and frontier. For all of the factors related to the option price, how to master related volatility is the most important, and also the most difficult. So, the related statistical work of data and programming language should not be ignored .In today's advanced foreign financial institutions, $\mathrm{R}$ language is widely used instead of $\mathrm{C}$ language, which accompanied with a large number of Package covering many complicated mathematical calculating tools, thus making the relevant pricing problems simple and feasible .Therefore, in view of the existing FX options trading as well as GFO tradings within the territory of China in the future, the related technical operation and editions must be carried on the detailed research. Especially in the aspect of programming, we should be having the relevant pricing model on the basis of deep understanding; meanwhile, for a large amount of digital parameters and structural factors, under the premise of detailed and serious statistics, we can refer to DerivaGem Software System for pricing GFO's value; finally, we should use R language, create our own pricing model, then setting up our own terminal platform for GFO tradings.

\section{Conclusion}

As Chinese old saying - "every journey begins with one step", for such a macro and complex financial problem, we should probe its pricing mechanism first, and then in the process of study, we will experience all kinds of essential problems, then analyzing them, finally finding the way to solve them. The author believes that: as long as studying earnestly, controlling rightly, China's financial derivatives market is bound to develop vigorously and orderly; the department of industrial and agricultural production in our country, especially the small and medium-sized enterprises, will benefit from it, and a virtuous cycle of the economy in our country will get achievement in the future.

\section{References}

Hong-Zhong Liu. (2008). Learning of the investment. 9th edition. Beijing Higher Education Press, 2008 (4).

John C Hull. (2009). Risk Management and Financial Institutions Peking. China Machine Press, 2009(9).

McCarthy, Ed. (2012). Structural Inefficiency, CFA Magazine, July-August 2012.

McDonald, Robert L. (2006). Derivative Markets, 2nd Ed.2006, Addison-Wesley, Pearson Education.

Michael Lovelady. (2013). Visual Quantitative Finance: A New Look at Option Pricing, Risk Management, and Structured Securities. Pearson Education, Inc. April 2013. 